\title{
First-Year Common Engineering Curriculum for the BC POST-SECONDARY SECTOR'
}

\author{
Brian Dick \\ Faculty of Science and Technology, Vancouver Island University \\ brian.dick@viu.ca
}

\begin{abstract}
Demand for engineering education has grown in recognition of its importance to the provincial economy, while engineering education capacity continues to lag. Engineering schools in British Columbia traditionally offer a common first-year of study that provides a foundation of science, mathematics, and engineering design before students specialize in second year. The British Columbia Council on Admission and Transfer (BCCAT) Engineering Articulation committee believed this transition served as a natural transfer point and undertook a year-long consultative process to establish the feasibility of developing a common, first-year engineering curriculum within the BC post-secondary sector.
\end{abstract}

This study found that although there exists some diversity within the first-year engineering programs at accredited receiving institutions, sufficient curriculum overlap allowed for a sector-wide common first-year engineering curriculum. This proposed curriculum suggests a content framework for students in all regions of the province to begin the first year of engineering studies at their institution of choice, and subsequently transfer to any of the major research institutions for degree completion.

Keywords: Articulation, Engineering Education, First-year Engineering Curriculum, Student Access, Student Learning Environment, Student Mobility, BC Transfer System

\section{INTRODUCTION}

Between 2015 and 2024, BC industry and employers will have to rely more heavily on new entrants (newly trained and new to the labour force) and immigration to meet the demand for engineers, particularly in regions outside of Metro Vancouver and southern Vancouver Island. Indeed, during this period, the Asia Pacific Gateway Skills Table, a not-for-profit, regional partnership between labour, business, and education and training institutions, predicts this occupational demand will outstrip supply by up to $10 \%$, thus ensuring a tight labour market that may impact economic growth in the province [8].
While the gap between demand and supply remains, the capacity in engineering education in $\mathrm{BC}$ continues to lag comparable provinces in Canada. For example, on a per capita basis, the number of engineering graduates in $\mathrm{BC}$ is less than that in Alberta, and only approximately $70 \%$ of that in Ontario and Quebec [7]. Further, qualified applicants for engineering seats in the province continues to rise, resulting in an increased focus on grades as an entrance barrier for students starting their engineering education [. Hence, there is a need to increase the capacity of engineering education in the province, provide diverse pathways to the profession, and improve the likelihood of engineering graduates locating in regions of high need.

\subsection{The BC Transfer System}

The BC Council on Admissions and Transfer (BCCAT) oversees the BC Transfer system, which connects BC postsecondary institutions, the education ministries, and the public and private education sectors. The BC Transfer system is a well-established tool to support student mobility (Figure 1) in the province; about one-third of the student population within the BC post-secondary system end their study at a different institution from which they started [6].

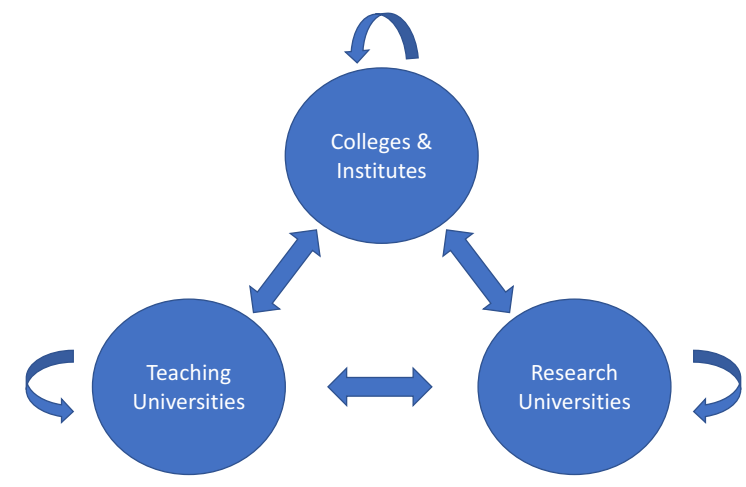

Fig. 1. Student Mobility in the BC Transfer System

To manage the transfer system, BCCAT provides and supports 67 autonomous articulation committees, each designed for a specific area of discipline [5].

${ }^{1}$ Content drawn from primarily from Ref [9] 
For engineering, the BCCAT Engineering Articulation Committee consists of:

- Six major research universities in $\mathrm{BC}^{2}$ including the University of British Columba - Point Grey campus (UBC-V), the University of British Columbia - Okanagan Campus (UBC-O), Simon Fraser University - Burnaby campus (SFU-B), Simon Fraser University - Surrey campus (SFUS), the University of Northern British Columbia (UNBC), and the University of Victoria (UVic)

- 17 public and private colleges and teaching intensive universities ${ }^{3}$

- The Association of Professional Engineers and Geoscientists of BC (APEGBC)

This committee has had an on-going conversation during prior annual meetings on how best to enhance access to engineering education within the province by facilitating transfer paths between (primarily) the college/teaching intensive university sector (i.e. sending institutions) and the major research universities (i.e. receiving institutions). Typically, receiving institutions offer a common first-year of study providing a foundation of science, mathematics, and engineering design before students specialize in second year. However, each receiving institution has traditionally had differing needs within that foundational year requiring sending institutions to offer courses tailored for specific transfer pathways. In other words, students starting their studies at a sending institution (e.g. Vancouver Island University) may be able to complete the full transfer path for UVic, but only a portion of the transfer path for SFU-S. This difference limited student mobility within the post-secondary system and reduced access to engineering education.

For comparison, the size of the first-year intake for selected institutions in the province are shown in Table 1.

Table 1: First-Year Intake (in 2015)

\begin{tabular}{|c|c|}
\hline Institution & Students Admitted \\
\hline $\begin{array}{c}\text { Simon Fraser University } \\
\text { (Burnaby Campus) }\end{array}$ & 250 \\
\hline $\begin{array}{c}\text { University of British Columbia } \\
\text { (Okanagan Campus) }\end{array}$ & 300 \\
\hline $\begin{array}{c}\text { University of British Columbia } \\
\text { (Vancouver Campus) }\end{array}$ & 800 \\
\hline University of Victoria & 450 \\
\hline Sending Institutions & $\sim 300$ \\
\hline
\end{tabular}

${ }^{2}$ For the purpose of this study, the Burnaby and Surrey campus of Simon Fraser University and the Okanagan and Point Grey campuses of the University of British Columbia were deemed sufficiently different in terms of their requirements to be treated as separate entities.

${ }^{3}$ Camosun College, Capilano University, College of New Caledonia, College of the Rockies, Columbia College, Douglas College, Kwantlen
Recent accreditation and student feedback at both UVic and UBC-V supported inclusion of engineering design courses within the first-year curriculum [1,3]. This inclusion resulted in a closer alignment of their first-year curricula, and allowed sending institutions to develop a common transfer pathway to both institutions. For example, Vancouver Island University (VIU) negotiated a formal transfer agreement with both UBC-V and UVic based on a common first-year curriculum. It subsequently signed an agreement with SFU-B based on a similar model, thus creating assured access for its students to most of the second-year engineering seat capacity in the province. This, and work at other institutions, provided an opportunity for the BCCAT Engineering Articulation committee to examine the feasibility of developing a shared set of first-year competency requirements sectorwide. At their 2014 annual meeting, the committee requested and obtained support for this work through the BCCAT Transfer Innovation fund and suggested that, if adopted, a common first-year curriculum could:

- Recognize the diverse learning pathways taken by student when obtaining an engineering degree.

- Provide clarity in the transfer process for both sending and receiving institutions.

- Improve program delivery efficiency at sending institutions

- Assist smaller institutions in developing an engineering focus, creating opportunities for community engagement and partnerships

- Improve the student learning environment (e.g stronger cohort development, student support)

- Enhance quality reporting for accreditation processes

\section{CONSULTATION PROCESS}

The robust conversation surrounding engineering transfer at the BCCAT Engineering Articulation committee, as well as the impact changes to the first-year curriculum could have at, primarily, sending institutions, demanded a rich and inclusive consultation process (see Figure 2) that included considerable stakeholder input. In addition to the sending and receiving institution membership on the articulation committee, BCCAT, and APEGBC input were also solicited, and further feedback was obtained from the Alberta Council of Admissions and Transfer (ACAD), the Engineering Graduate Attribute

Polytechnic University, Langara College, Northern Lights College, Northwest Community College, Okanagan College, Selkirk College, Trinity Western University, Thompson Rivers University, University of the Fraser Valley, Vancouver Community College, Vancouver Island University 
Development (EGAD) group, and the Canadian Engineering Accreditation Board (CEAB). When possible, the individual needs of sending institutions were considered throughout the consultation process, although the accreditation requirements of the receiving institutions were treated as paramount.

Details of engineering program offerings were obtained from individual institution's publically available program pages and confirmed with the principal contact at that institution whenever possible. From this input, an initial discussion paper was written which included five recommendations focusing on curriculum, disseminating of transfer agreements, and instructor credentials. This discussion paper was circulated and brought forward to a round-table discussion with all receiving institutions, as well as BCCAT, and the engineering articulation chair. Upon revision of this paper, it was distributed to all members of the articulation committee for discussion at the 2016 annual meeting. Feedback from all these stakeholder conversations were synthesized into a draft final report which was distributed, again, to all stakeholders for comment before submission to BCCAT and publication on their website.

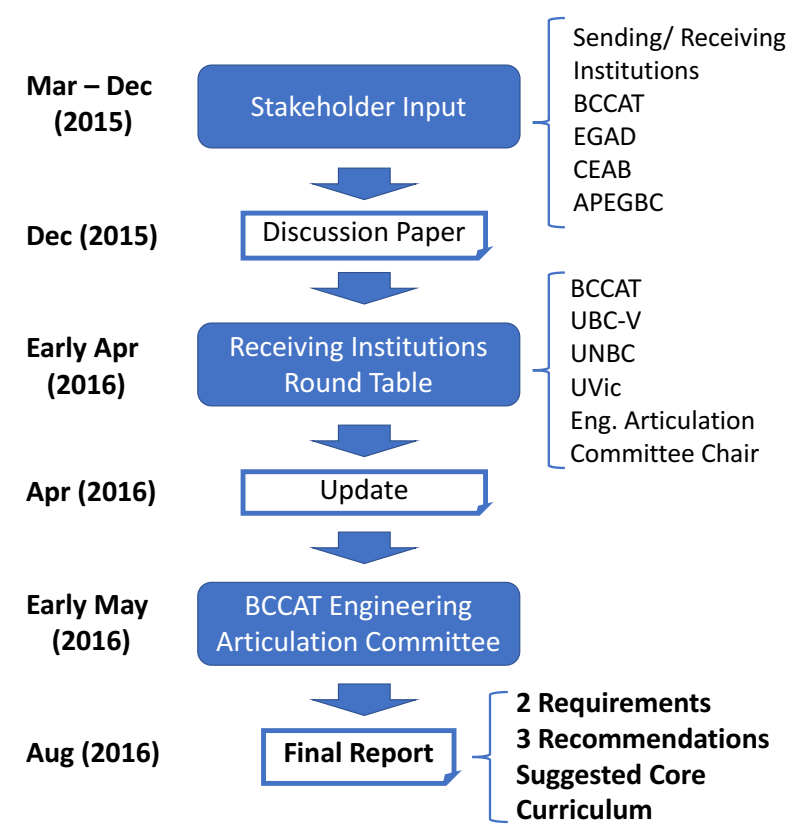

Fig. 2. Feasibility Study: Consultation Process

\section{RESULTS AND DISCUSSION}

The consultation process resulted in two requirements and three recommendations, in addition to a suggested shared first-year engineering curriculum.

\subsection{Requirements}

The two requirements identified essential aspects of the first-year curriculum at all institutions outside the topical coverage. These included:

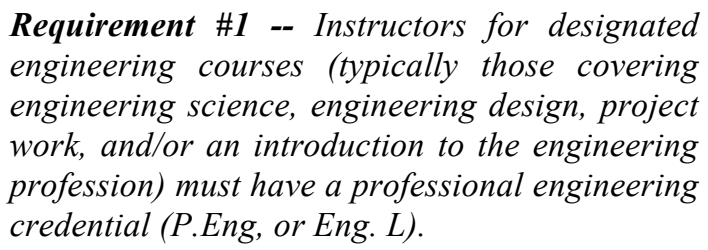

As the CEAB applies a minimum path analysis to the counting of accreditation units (AUs), the student graduation pathway that results in the lowest AU count strongly impacts the accreditation outcome [10]. Hence, to fulfill their accreditation requirements, receiving institutions must be able to show that all students in designated engineering courses (including those at sending institutions) have been instructed by an engineering professional. Although promoting access to engineering education through colleges and teaching universities is recognized as a strength of the $\mathrm{BC}$ Transfer system, it does result in the common practice of receiving institutions shifting all AU requirements outside of first-year to ensure that their accreditation needs are met. If the first-year curriculum for all incoming students could be qualified under $\mathrm{CEAB}$ there would be more flexibility available within the overall degree.

APEGBC has recently provided a pathway to the Eng.L designation for all instructors (including those at the $1 \mathrm{st}$ and 2 nd year level) of engineering science or design. This pathway is shown in Figure 3 and requires a minimum of 10 years engineering instruction experience, as well as successful completion of the professional practices exam and in-person panel interview. The Eng.L is a recognized engineering professional designation, and can be used to support an institution's accreditation. Indeed, the author was the first in the province to follow this pathway and receive his Eng.L.

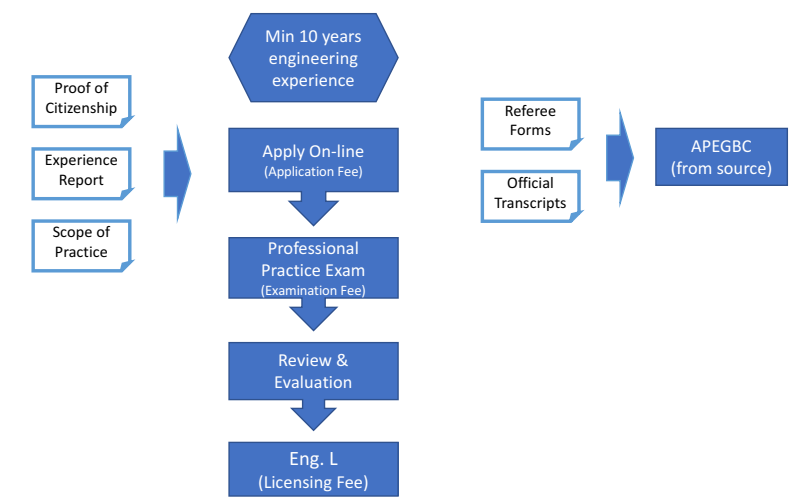

Fig. 3. Application Process for Eng.L. Credential 
Requirement \#2 -- All students will complete Workplace Hazardous Materials Information System (WHMIS) training before undertaking course lab work.

There has been an increasing effort to better empower students to proactively adopt the principals of health and safety management. For example, Minerva Canada is a non-profit that is working with post-secondary institutions to include health and safety management in the engineering curriculum. In $\mathrm{BC}$, most institutions do not require WHMIS training for students, but are open to its inclusion, although one of the receiving institutions (i.e. Simon Fraser University) does have this requirement. Further, WorkSafe $\mathrm{BC}$ regulations demand that employers ensure all workers (including students who may be working in a laboratory environment) have WHMIS training. As much of the proposed project work for students is likely to take place in spaces where safety of students is a concern, this recommendation was deemed a necessary inclusion going forward.

\subsection{Recommendations}

Three recommendations were provided to help strengthen and support the student transfer pathway process. These included:

Recommendation \#1 -- Develop a process to track student progression and success through their academic careers with respect to their study pathway.

There is strong support by all post-secondary institutions in the province to maintain and make available student success throughout their academic careers, although a number of challenges have been identified (e.g. insufficient resources, anonymizing data, partial versus full-year transfers). Sending institutions require this knowledge to ensure that their programs are adequately preparing a student for success. Receiving institutions require this data to assure $\mathrm{CEAB}$ of their program quality, no matter the student's individual study path. These latter institutions have been working towards better tracking student progress and reporting back their partner institutions, and generally the data suggests that student success is not dependent on their institutional path i.e. students transferring into second year at a receiving institution have the same success rate as a student who arrived by direct entry. To further assist in this data monitoring effort, the in-progress BCCAT Student Transitions Project has been suggested as a means of collecting student transfer data while adhering to the Freedom of Information and Privacy Protection Act (FOIPPA) of British Columbia.

\begin{abstract}
Recommendation \#2 -- Current transfer agreements, particularly those that provide a block transfer of courses between sending and receiving institutions to be made available to the Engineering Articulation Committee with the goal of building a common transfer agreement framework applicable for all post-secondary institutions within the province.
\end{abstract}

Recommendation \#3 -- Sending institutions encapsulate their first-year engineering curriculum as a recognized credential and aligned to the common engineering core curriculum.

Developing an engineering student's professional identity is an important outcome of engineering education, and is generally thought to improve student retention in the field [2]. Historically, sending institutions in BC do not have an engineering department and, instead, manage the engineering transfer curriculum through a related department or area (e.g. physics, math). The engineering transfer curriculum is generally arranged as a set of firstyear courses that, collectively, provide a transfer path to specific receiving institutions. The connection between the student and their chosen profession is therefore less defined. In contrast, although course content and/or individual instructors are highly impactful on engaging students with their profession, newly admitted students at receiving institutions are likely to more immediately identify as engineering students through their learning environment; first-week activities, presence of lower and upper-level engineering students, extracurricular student clubs, as well as enrolment within a department and/or faculty focused on their profession.

The CEAB shift towards graduate attributes, implicitly requires students to be introduced earlier to concepts such as professionalism, engineering ethics, and the role of the engineer in society, and creates an opportunity for sending institutions to consider broader program level objectives, enhance their students' learning experience, and promote engineering as a career pathway within their local communities. Structuring the first-year engineering transfer curriculum as a recognized credential aligned to the common core requirements may help realize this opportunity.

A number of sending institutions in British Columbia have recently moved towards a first-year engineering experience program model (e.g., certificate program in engineering at Kwantlen Polytechnic University; engineering foundations certificate at Douglas College). These cohort-centred programs have been shown to promote a supportive environment for students; enhancing their self-awareness, engineering identity, peer instruction, networking, and 
team building. In the author's experience, creating the Fundamentals of Engineering certificate program at VIU has provided a number of additional benefits to the above including:

- Increased profile of engineering both within the institution, the K-12 system, and local community;

- Improved student intake management and tracking student progress post-transfer;

- Improved resourcing/community sponsorship to aid program growth and enhance the student learning experience;

- $\quad$ Strengthened connections to the local engineering community (e.g., local APEGBC branch); and

- Opportunities to enhance students' experiential learning (e.g., co-op, field trips).

\subsection{Core Curriculum}

The core curriculum is intended to capture the minimum threshold of topical coverage that is acceptable by all receiving institutions and can be treated as equivalent to their first year of studies. As shown in Figure 4, the shared curriculum was not intended to describe the admission process for individual receiving institutions.

The common first-year engineering curriculum was informed by the CEAB guidelines, including both the input-based AU system and the output-based graduate attribute (GA) system, and built using existing articulation agreements in the BC post-secondary sector as a foundation. When course-by-course articulation pathways did not exist, block transfers and course and program learning outcomes were evaluated with emphasis on their impact on student success in subsequent years of study. Further, to maintain and enhance capacity to engineering education and improve efficiency of program delivery, alignment with typical Bachelor of Science requirements at sending institutions was considered.

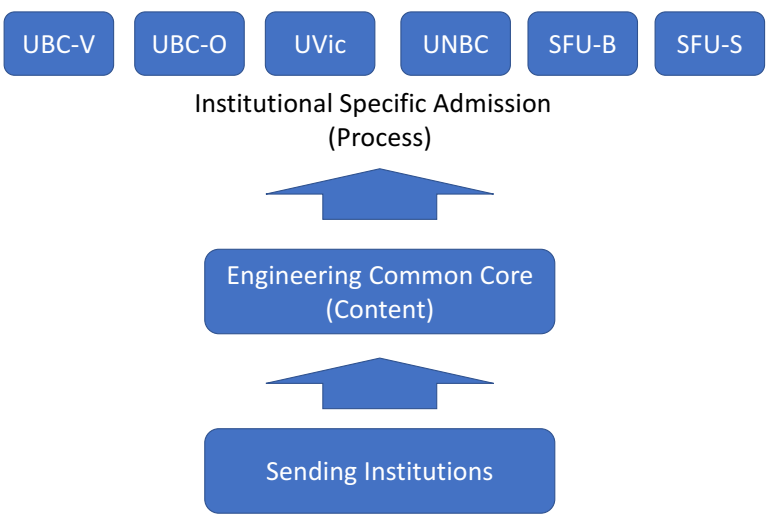

Fig. 4. Student Transfer Process
The common engineering curriculum has been described in terms of twelve course blocks (see Table 2). Specific course details can be found in Ref [9].

Table 2: Common Curriculum Content.

\begin{tabular}{|c|l|}
\hline Course & \multicolumn{1}{|c|}{ Description } \\
\hline CALC I/II & $\begin{array}{l}\text { Standardized Calculus I/II } \\
\text { including Sequences and Series, } \\
\text { Polar Coordinates, Parametric } \\
\text { Equations }\end{array}$ \\
\hline LALG I & Linear Algebra \\
\hline PHYS I/II/II & $\begin{array}{l}\text { Statics and Dynamics, Waves, } \\
\text { Electromagnetism, } \\
\text { Thermodynamics }\end{array}$ \\
\hline ENGL I/II & University/Technical Writing \\
\hline CSCI I & Computer Programming \\
\hline CHEM I+ & $\begin{array}{l}\text { Combined Learning Outcomes of } \\
\text { standard BSc CHEM I/II }\end{array}$ \\
\hline ENGR I/II & Engineering Design I/II \\
\hline
\end{tabular}

\subsection{Design Curriculum}

There has been a considerable shift in the approach to engineering education; although theory is still emphasized, it is generally recognized that project-based, and teambased learning can better establish a connection between students and the engineering profession $[1,3,4]$. The Canadian Engineering Accreditation Board has increasingly demanded that engineering design content be brought earlier into the curriculum.

Design projects introduce many of the twelve graduate attributes such as individual and team work, communication, professionalism, impact of engineering on society, ethics and equality, economics and project management, and life-long learning in addition to engineering design itself, and all the major research institutions in $\mathrm{BC}$ offer a design project as either a course or significant project. These learning outcomes would be replicated at sending institutions through the suggested ENGR I/II course block, while providing flexibility in instruction; namely, what projects are undertaken may differ from sending institution to sending institution without impacting the overall learning objectives of the course. In the author's experience, this flexibility in project design creates an opportunity for institutions to enhance their partnerships with local industry and the profession, expose students to engineering activities within their communities, and develop local networking opportunities that may encourage students to return after their studies.

The ENGR I/II curriculum is consistent with the accreditation and technical needs of all major research institutions in the province. ENGR I has a focus on broadly introducing students to the engineering design process and team work through a number of smaller projects. ENGR II 
requires that students demonstrate the ability to successfully plan, deliver, and communicate a major project using engineering design principles and the tools and resources introduced throughout the ENGR I/II curriculum. Engineering ethics and professionalism, and the engineer's impact on society are to be embedded throughout the project work and lectures. Integrating ENGR II and ENGL II (Technical Writing) may also further strengthen the student learning experience.

Two of the requirements placed upon the design courses and specific to the BC post-secondary system is the need for at least half of one course to be based around a computer-aided drawing (CAD) project, while half of one course is to be based around concepts of sustainability/designing for the environment. These two requirements are not seen by either sending or receiving institutions as being restrictive: Many sending institutions already offer a one-term CAD course due to historical transfer agreements with UBC-V, and there is broad support in both the community and profession (e.g. Engineers Canada suggested Code of Ethics, APEGBC Code of Ethics) to introduce students to sustainability principles and projects related their application.

\section{CONCLUSION}

This study suggests that a sector-wide approach to enhance access to engineering education in $\mathrm{BC}$ by:

- Introducing a common core, first-year curriculum applicable for all post-secondary institutions in BC

- Improving quality assurance processes

- $\quad$ Requiring formal student safety training

- $\quad$ Promoting engineering as a program at sending institutions to improve resourcing, focus, and visibility.

- Encouraging community and professional partnerships

The BCCAT Engineering Articulation committee accepted the feasibility report at their 2016 meeting and requested that a proposal be submitted to the BCCAT Transfer Innovation fund for support to move forward with implementing the report's recommendations.

\section{Acknowledgements}

This activity has resulted from the active contribution of all BCCAT Engineering Articulation members, past and present, BCCAT, and APEGBC.

Specific recognition is due to:

- $\quad$ Todd Stuckless (Langara College) - co-author of the BCCAT TIP proposal, key contributor to this work, and past chair of the BCCAT Engineering Articulation Committee.

- LillAnne Jackson, Carol Jaeger, and their respective teams at UVic and UBC-V for their incredible work supporting this project.

Funding support has been provided by a BCCAT Transfer Innovation grant.

\section{References}

[1] McGuire, M., Li, K. F., Gebali, F., "Teaching Design to First-Year Engineering Students," in Proc. Canadian Engineering Education Association CEEA15 Conf., (Hamilton, ON; 31-May to 03-Jun 2015), Paper 001.

[2] Eliot, M., Turns, J, "Constructing Professional Portfolios: Sense-Making and Professional Identity Development for Engineering Undergraduates", J. Eng. Education, 100 (2011)

[3] Ostafichuk, P. M., Jaeger, C.P., Nakane, J., Nesbit, S., Ellis, N., Sibley, J., "Redesigning the UBC First Year Introduction to Engineering: Successes and Challenges," in Proc. Canadian Engineering Education Association CEEA16 Conf., (Halifax, NS; 19-22 June 2016), Paper 135.

[4] Rogers, C., Cyr, M., McDonald, J., Nocera, T., "The Design and Performance of Musical Instruments", in Proc. American Society for Engineering Education Conf. (Washington, DC, Jun-2000)

[5] Articulation Committees in the BC Transfer System. BCCAT, 2014 Available as of May 27, 2017 from www.bccat.ca/pubs/articulationcommittees.pdf

[6] BC Transfer Students: Profile and Performance Report (2008/09 - 2012/13) Available as of Apr 27, 2017 from www.bccat.ca/pubs/ProfileReport_May2015.pdf

[7] Canadian Engineers for Tomorrow, Engineers Canada (2015) Available as of Apr 26, 2017 from engineerscanada.ca/sites/default/files/EnrolmentReport2014e-r2.pdf

[8] Engineers, Geoscientists, Technologists and Technicians, Labour Market Information (2015-2024), Executive summary. Available as of May 27, 2017 from www.lmionline.ca/wpcontent/uploads/2015/10/EGTT_HighlightsSummary_26Oct2015.pdf

[9] First-Year Core Engineering Curriculum for the BC PostSecondary Sector - Final Report. BCCAT, 2016 Available as of May 27, 2017 from www.bccat.ca/pubs/Engineering Final Report - v121.pdf

[10] 2016 Accreditation Criteria and Procedures. Canadian Engineering Accreditation Board (CEAB), 2016 \{ISSN 1708-8054\} Available as of Apr 26, 2017 from engineerscanada.ca/sites/default/files/accreditation-criteriaprocedures-2016-final.pdf 